\title{
Effects of IL-2 treatment on different compartments of the irradiated rat lung analysed by bronchoalveolar lavage and lung tissue morphology
}

\author{
C. Yi-Qing*, L. Bjermer**, Ö, Fröjd*, O. Nettelbladt ${ }^{+}$, \\ A. Karlsson-Parra++, R. Henriksson*
}

Effects of IL-2 treatment on different compartments of the irradiated rat lung analysed by bronchoalveolar lavage and lung tissue morphology. C. Yi-Qing, L. Bjermer, Ö, Fröjd, O. Nettelbladt, A. Karlsson-Parra, R. Henriksson. CERS Journals Ltd 1995.

ABSTRACT: In recent years, interleukin-2 (IL-2) has been used as an immunomodulatory agent in the treatment of various malignant tumours. However, this treatment has been limited by serious side-effects, including toxic reactions in the lung. The effects of IL-2 treatment on inflammatory cell populations in the normal and irradiated rat lung were investigated in this study.

IL-2 was continuously administered as a subcutaneous infusion over a 6 week study period. Irradiation was given in a single dose $(25 \mathrm{~Gy})$ the day after starting IL-2 treatment. Evaluation with bronchoalveolar lavage fluid (BALF) analysis and lung tissue morphology was made 6 weeks after irradiation.

In nonirradiated rats, IL-2 treatment induced significant increases in the total number of inflammatory cells in the perivascular, interstitial and peribronchial tissues as well as in the alveolar space. These increases were not reflected in BALF; on the contrary, a significant decrease of the total numbers of inflammatory cells was found in BALF. Irradiation alone caused a more pronounced inflammatory response with significant increases of all inflammatory cells in all lung compartments, which was also reflected in BALF. Concomitant treatment with IL-2 and irradiation induced an enhanced accumulation of inflammatory cells in the perivascular and peribronchial tissues compared with irradiation alone.

Thus, both irradiation and IL-2 treatment induce inflammatory reactions in the lung, but there were few signs of synergistic effects seen in this study. Furthermore, the results also emphasize the difficulties in making sophisticated conclusions from BALF analyses alone.

Eur Respir J., 1995, 8, 1872-1878.
*Dept of Oncology, University Hospital of Umeå, Sweden. **Dept of Lung Medicine, University Hospital of Trondheim, Norway. +Dept of Lung Medicine and ++Immunology, University Hospital or Uppsala, Sweden.

Correspondence: L. Bjermer

Dept of Lung Medicine

University Hospital

N-7006 Trondheim

Norway

Keywords: Bronchoalveolar lavage interleukin-2

interleukins

irradiation

rat

Received: August 171994

Accepted after revision August 301995

This study was supported by grants from the Swedish Society Against Cancer and the Lions Foundation, Umeå, Sweden.
Interleukin-2 (IL-2) is a potent regulator of the immune system. It is able to increase the tumour bearing host resistance to neoblastic disorders $[1,2]$. Through expansion of cytolytic T-cell clones, IL-2 augments cellular immunity to tumour associated antigens [3, 4]. Thus, treatment with IL-2 would theoretically offer intriguing possibilities in the therapy of malignant tumours. However, serious side-effects, such as convulsions and severe hypertension, associated with IL-2 treatment have considerably hampered the initial enthusiasm (for review see [5]). Moreover, during IL-2 treatment, lung complications with respiratory insufficiency have been reported [6]. It is believed that these pulmonary reactions are explained by a combined effect of IL-2 induced cardiac toxicity and capillary leak syndrome [5]. Thus, IL-2 is a potent modulator of the immune system and it is possible that the lung toxicity may also be mediated by an IL-2-induced immune reaction, disparate from the effect on the vascular permeability. This question has, to our knowledge, not yet been investigated.
Irradiation is known to induce a specific tissue reaction both in humans [7, 8] and animals [9]. From bronchoalveolar lavage (BAL) studies on patients with localized breast cancer receiving postoperative radiation therapy, we have previously found an inflammation in BAL fluid (BALF) characterized by increase of lymphocytes and mast cells, paralleled by an increase of connective tissue associated substances, such as hyaluronan, fibronectin and procollagen-III-peptide [7, 8]. These findings inspired us to develop an animal model facilitating combined analysis of BAL and tissue morphology in one and the same animal. We found that the irradiation-induced tissue reaction in the lung was characterized by a pronounced increase of mast cells and mononuclear cells in the alveolar tissue, closely correlated with an increase of hyaluronan [9]. In contrast, BAL was characterized by an increase of neutrophils, lymphocytes and, to a much lesser degree, of mast cells, indicating that BAL differential cell counting did not fully reflect the events in the alveolar region. Moreover, hyaluronan in contrast to 
cellular differential counting, closely reflected the deposition seen in the alveolar tissue [9]. It is thus reasonable to believe that those animal data are also partly relevant in the human situation. BAL is thought to reflect inflammatory events in the lower airways, and larger lavage volumes have been recommended in order to secure sampling of the alveolar regions [10]. Factors such as anatomical constitution, lavage site and cellular activity/ adhesiveness (i.e. induced by cytokines) may influence the BAL results.

The aim of the present study was to determine whether IL-2 could induce an inflammatory reaction in the lungs and, if so, how this was reflected by BAL. Another aim was to see whether IL-2 treatment influenced the radiation-induced reaction in the rat lung, with special emphasis upon the combined use of tissue morphological analysis and BAL.

\section{Materials and methods}

\section{Animals}

Thirty five male Spraque-Dawley rats, aged 16 weeks and weighing about $300 \mathrm{~g}$ each at the start of the experiment, were used. The experiments were approved by the Ethics Committee (No. A103/90), and handled according to the regulation of the Swedish Animal Protection Act (SF 1988.534). The animals were given standard rat pellets and tap water ad libitum.

\section{Study design}

The rats were divided into four groups, eight animals in each group (11 animals in the control group). One group was treated only with interleukin-2 (IL-2), one group was only irradiated $(\mathrm{R})$, one group was treated with interleukin-2 and irradiation (IL-2+R), and one group of rats served as non-IL-2 nonirradiated controls (C). In four of the control animals, sham treatment was performed. In these animals, capsules with buffered saline and albumin were implanted. No difference could be found in weight gain or morphology between these animals and the remaining seven controls (data not shown).

\section{Methods}

Interleukin-2 administration. IL-2 treatment was started one day before the irradiation. The method of administration has been described in more detail previously [11]. Briefly, IL-2 was continuously delivered as a subcutaneous infusion using an Alzet micro-osmolic pump (model 2002) during the experimental period (Alza Corporation, Palo Alto, Ca, USA), with a steady delivery of $0.5 \mu \mathrm{L} \cdot \mathrm{h}^{-1}$ for 14 days. The pumps were filled with IL-2 dissolved in buffered saline with $0.5 \%$ human albumin to a concentration of $1,800,000$ IU in 200 $\mu \mathrm{L}$, which corresponds to a mean daily dose of 424,000
IU $\cdot \mathrm{kg}^{-1}$. This dose was selected based upon the work of others and our previous published data [11, 12], where we chose a dose with expected biological effect throughout the treatment period, but with minor signs of animal morbidity, measured as weight gain, compared to nontreated controls. Before treatment, the animals were anaesthetized by means of an intraperitoneal injection of a solution, $0.2 \mathrm{~mL} \cdot 100 \mathrm{~g}^{-1}$ body weight, of equal parts of Dormicum ${ }^{\circledR}$ (Midazolam $5 \mathrm{mg} \cdot \mathrm{mL}^{-1}$, Roche, Basel, Switzerland) and Hypnorm ${ }^{\circledR}$ (Fluanizone $10 \mathrm{mg} \cdot \mathrm{mL}^{-1}$, Janssen Pharmaceutical, Beerse, Belgium). The pump was embedded subcutaneously just below the neck. A new pump with fresh solution was implanted, by the same method, every 14 days. In total, three capsules were implanted throughout the whole observation period.

Radiation. The day after starting the IL-2 treatment, IL- $2+\mathrm{R}$ and $\mathrm{R}$ rats were anaesthetized by intraperitoneal injection, $0.2 \mathrm{~mL} \cdot 100 \mathrm{~g}^{-1}$ body weight, of DormicumHypnorm as described previously $[9,13]$. The rats were placed in supine position in a body shaped box. The lower parts of the lungs were irradiated with photon beams $6 \mathrm{mV}$ (dose rate $2.19 \mathrm{~Gy}$ ) to an accumulated mean target dose of $25 \mathrm{~Gy}$. The nonirradiated parts were shielded by a block of Rose's metal, $80 \mathrm{~mm}$ thick. With this dose, a significant radiation induced tissue reaction was achieved at the selected time-point; however, this was less intensive than previously found after $30 \mathrm{~Gy}$ [9], and after 28 Gy [13]. The animals were sacrificed 6 weeks after irradiation.

Bronchoalveolar lavage (BAL). The rats were deeply anaesthetized by intraperitoneal injections of DormicumHypnorm ${ }^{\circledR}$. The animals were thereafter sacrificed by exsanguination, blood samples collected from the heart, the chest wall opened and the lungs and trachea dissected free in situ. After tracheotomy, a small plastic tube with a stiff internal introducer was inserted into the trachea and placed in the right main bronchus. The catheter position allowed only the lower and the middle lobes to be lavaged. The left main bronchus was compressed and 3 $\mathrm{mL}$ phosphate buffered saline (PBS) solution was instilled through the tubing and thereafter gently aspirated. The lavage procedure was repeated three times with 2 $\mathrm{mL}$ of PBS in each aliquot. The lungs were thereafter further processed for histological sections.

Analysis of bronchoalveolar lavage fluid (BALF) cells. The BALF was kept on ice and total numbers of cells were counted in a Bürker chamber. The lavage fluid was centrifuged at $400 \times \mathrm{g}$ for $15 \mathrm{~min}$ at $4^{\circ} \mathrm{C}$. The cell pellet was resuspended in a balanced salt solution to a concentration of $10^{6}$ cells $\cdot \mathrm{mL}^{-1}$. Slides were prepared using a cytocentrifuge (Cytospin Shandon, Southern Ltd, Runcorn, UK) at $96 \times \mathrm{g}$ for $5 \mathrm{~min}$, giving approximately 50,000 cells $\cdot$ slide $^{-1}$. The cytospin slides were stained with May-Grünwald Giemsa and 200 nonepithelial cells were counted to determine the proportions of macrophages, lymphocytes, neutrophils and eosinophils. The result were presented as percentage of all cells and as total cells. $\mathrm{mL}^{-1} \mathrm{BALF}$. 
Morphological analysis. Immediately after BAL, the right lungs of every other rat were distended in situ to its total lung capacity by installation of a solution of either MILAB fixative $\left(0.2 \mathrm{~g} \mathrm{CaCl}_{2}, 0.2 \mathrm{~g} \mathrm{KH}_{2} \mathrm{PO}_{4}\right.$, $1.14 \mathrm{~g} \mathrm{Na}_{2} \mathrm{HPO}_{4}, 8 \mathrm{~g} \mathrm{NaCl}, 40 \mathrm{~mL}$ formaldehyde, dissolved in 1,000 $\mathrm{mL} \mathrm{H}_{2} \mathrm{O}$; MILAB AB, Malmö, Sweden) or IFAA $(0.6 \%$ formaldehyde and $0.5 \%$ acetic acid in distilled water). After compression of the right main bronchus, the left lungs from four randomly chosen rats in each group were infused under gravity with Histocon ${ }^{\circledR}$ (Histolab AB, Gothenburg, Sweden), for immunohistochemical staining at $4^{\circ} \mathrm{C}$ until it reached normal inflated size. The left lungs of the remaining four rats were fixed by installation of a solution of MILAB or IFAA. The lungs and hearts were then removed from the thorax.

The left lungs fixed in Histocon ${ }^{\circledR}$ were stored at $4{ }^{\circ} \mathrm{C}$ for not more than $60 \mathrm{~min}$. Thereafter, the specimens were snap frozen in chilled isopentane and stored at $-70^{\circ} \mathrm{C}$.

The lungs ( $\geq 6$ per group) fixed in MILAB were further processed in a microwave oven for $25 \mathrm{~s}$ giving the preparations a final temperature of $40-45^{\circ} \mathrm{C}$ and, thereafter, washed in buffered saline and kept in this solution until dehydration. The lungs ( $\geq 6$ per group) fixed in IFAA solution were kept in this solution until dehydration. After dehydration, the lungs were embedded in paraffin and $5 \mu \mathrm{m}$ thick sections were prepared.

Sections fixed in MILAB were stained with Luna's stain (Weigert's working haematoxylin with $0.2 \%$ Biebrich scarlet red solution, $1 \% \mathrm{HCl}$ in $70 \%$ ethanol, $0.5 \%$ aqueous lithium carbonate) and used to determine the total cell numbers and differential cell counts. Luna's stain was used as an alternative to haematoxylin-eosin, with easy detection of eosinophils in the tissue. Sections fixed in IFAA were stained with acid toluidine blue, counter stained with Mayer's acid haematoxylin and used for determination of mast cells in the alveolar interstitium [14]. Both the MILA and IFAA fixed lungs were stained with Masson's trichrome to visualize the increase of interstitial collagen 6 weeks after irradiation (data not shown). Total and differential cell counts (except staining of eosinophils) could be made on Masson trichrome as well as on Luna stained slides.

Since no significant difference was found in the interstitial cell numbers between the lavaged and the nonlavaged side (data not shown), both lungs were used for morphology. Total cell counts were made on four defined areas of lung tissue, the alveolar space, the lung interstitium (e.g. alveolar septal tissue), the peribronchial tissue and the perivascular tissue. Differential cell counts were made on BAL cytospin centrifuge slides and on cells present in the alveolar space. The macrophage population was divided into two groups, small to medium size macrophages (SMC) and big foamy rich vacuolized alveolar macrophages (BMC). In the tissue, it was not possible to differentiate between mononuclear cells, such as macrophages and lymphocytes, and therefore differentiation could only be made between mononuclear cells and polymorphonucleated cells (PMNs). Since no or very few eosinophils could be seen either in BAL, alveolar space or in the interstitial tissue it was assumed that the majority of PMNs consisted of neutrophils. The IFAA fixation procedure and the acid toluidine blue staining technique for mast cell counting impairs the general morphology, and it was difficult to differentiate between vascular and bronchial tissue. Therefore, for mast cell counts no differentiation was made between peribronchial and perivascular tissue.

Histocon ${ }^{\circledR}$ inflated frozen lungs (=4 per group) were used for immunoperoxidase staining to visualize T-cell subsets. Longitudinal acetone-fixed cryostat sections, 6 $\mu \mathrm{m}$ thick, including apex, hilar tissue and the base of the left lung, were processed for peroxidase-antiperoxidase (PAP) staining [15]. T-cell populations were identified by the $\mathrm{W} 3 / 13$ monoclonal antibody $(\mathrm{MoAb})$ reactive with a glycoprotein present on all T-cells and on a small amount of certain other leucocytes [16]. T-cell subpopulations were identified by the OX $8 \mathrm{MoAb}$ recognizing a homologue of the human CD8 antigen on rat suppressor/cytotoxic T-cells [17], and the W3/25 MoAb recognizing a homologue of the human $\mathrm{CD} 4$ antigen on rat helper T-cells and certain macrophages [18]. Preformed complexes of horseradish peroxidase and monoclonal mouse antihorseradish peroxidase antibody (diluted 1/500) were obtained from Dakopatts (Copenhagen, Denmark). The peroxidase reaction was developed with 3-amino-9-ethyl-carbazole [19], and the sections were counterstained with Mayer's haematoxylin. The dilutions of the antibodies were determined using sections from normal rat lymph nodes. Controls without the primary antibodies or with irrelevant antibodies produced no staining. Each specimen was also stained with haematoxylin and eosin.

All data from histological sections were calculated from 10 fields with an accumulated area of $0.113 \mathrm{~mm}^{2}$, and were counted at a magnification of $\times 480$ [13]. The results are presented as numbers of cells $\cdot \mathrm{mm}^{-3}$.

\section{Statistical analysis}

Wilcoxon's nonparametric rank sum test was used to analyse the data. A value of $p$ less than 0.05 was considered as the level of significance.

\section{Results}

\section{Effects of IL-2 treatment}

In histological sections, the total cell numbers in the alveolar space increased in the IL-2 treated group compared to the controls (fig. 1), mainly due to an increase of macrophages and lymphocytes (table 1). An increase of total cells was also seen in the lung interstitium, the peribronchial tissue and, most markedly, in the perivascular area (fig. 1).

IL-2 treatment caused an increase of T-cells in the perivascular area (fig. 2d). A few mast cells were located in the peribronchial/perivascular area, and in this area 


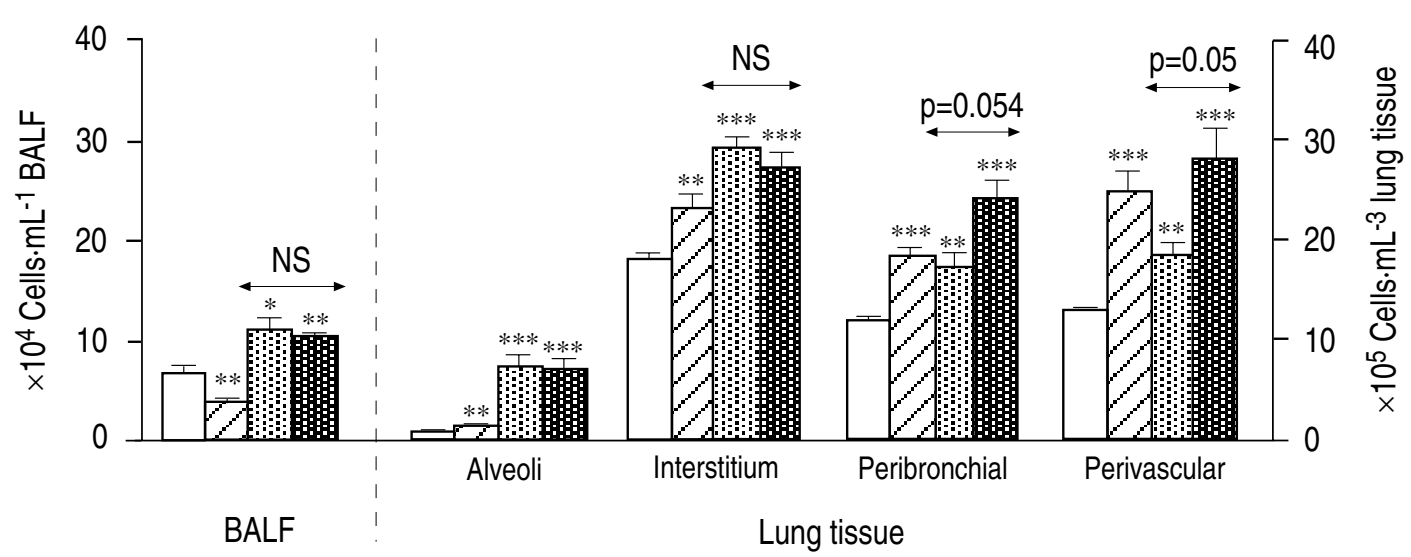

Fig. 1. - Total cell counts in bronchoalveolar lavage fluid (BALF) or lung tissue in rats evaluated 6 weeks after treatment. Bars indicate sEM.

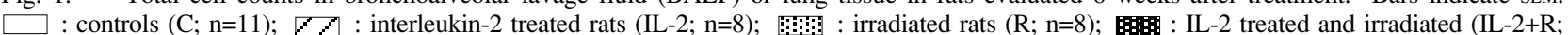
$\mathrm{n}=8$ ). Statistical comparisons between treated and controls were made with Wilcoxon's nonparametric rank sum test for unpaired samples, and flagged as *: $\mathrm{p}<0.05 ; * *: \mathrm{p}<0.01 ; * * *: \mathrm{p}<0.001$. Statistical comparisons between the IL-2 and IL-2+R groups are shown separately (two headed arrows).

Table 1. - Total number of cells in bronchoalveolar lavage fluid (BALF) or in the alveolar space from rats evaluated 6 weeks after treatment

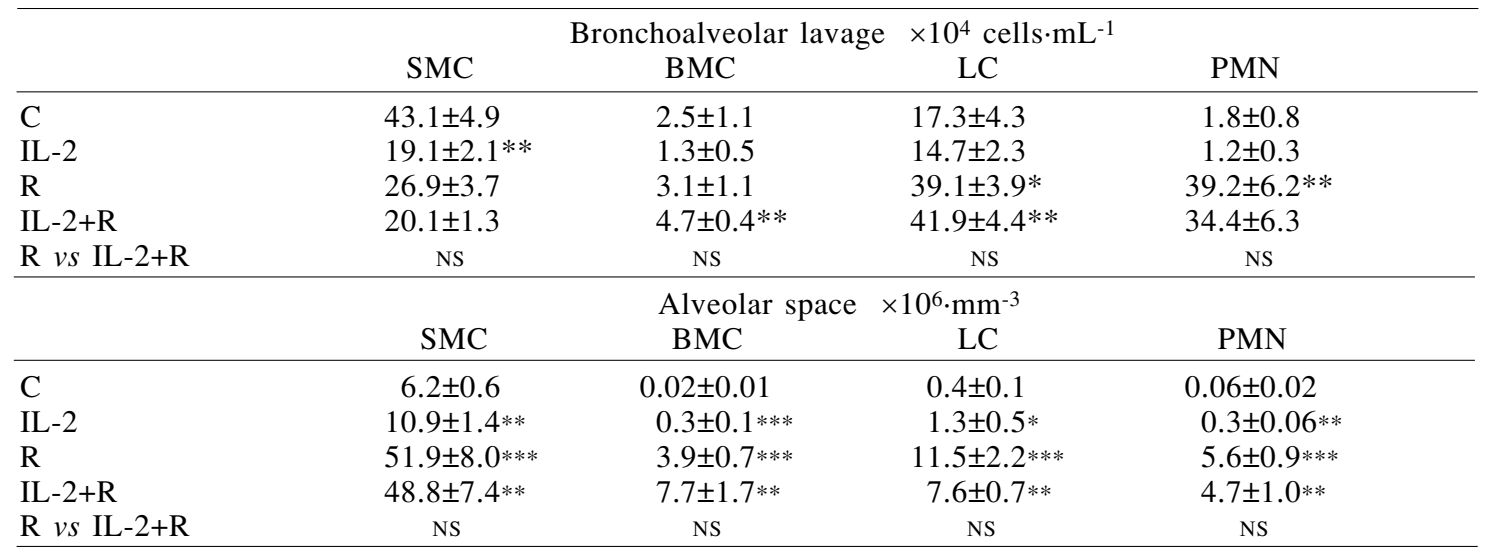

Values are presented as mean \pm sEM. There were eight animals in each treatment group and 11 controls. SMC: small to medium sized monocytes/macrophages; BMC: big macrophages; LC: lymphocytes; PMN: polymorphonucleated cells; C: controls; IL-2: interleukin-2 treated animals; R: irradiated animals; IL-2+R: IL-2 treated and irradiated; Ns: nonsignificant. *: $\mathrm{p}<0.05 ; * *: \mathrm{p}<0.01 ; * * *: \mathrm{p}<0.001$, compared to control rats.

IL-2 treatment caused twofold increase of mast cells compared to controls (table 2). No or very few mast cells could be seen in the alveolar space.

In marked contrast to histological findings, the total numbers of cells recovered in BALF was clearly reduced in the IL-2 group compared to untreated controls (fig. 1), mainly due to a decreased number of small to medium sized macrophages (table 1). No or very few eosinophils could be seen in any of the groups.

\section{Effects of irradiation}

A more than tenfold increase of total alveolar cells was found in the irradiated group compared to the controls (fig. 1). The relative increases of large macrophage-like cells, lymphocytes and PMNs was of the same magnitude, whereas the total increase of small macrophages accounted for $60 \%$ of the total cell increase (table 1). The total cell numbers were also increased in the interstitium, peribronchial and perivascular areas of the irradiated group compared to the controls (fig. 1). Compared to the response induced by IL-2 treatment alone, irradiation caused a more pronounced increase of total cells in the alveolar space and in the interstitium. In contrast, no difference in response could be seen in the peribronchial area, and in the perivascular tissue there was a tendency toward higher numbers of cells in the IL-2 treated group compared to the irradiated non-IL-2 treated group $(\mathrm{p}=0.054)$.

Irradiation caused a sixfold increase of $\mathrm{T}$-cells in the alveolar space. Both CD4+ and CD8+ cells were increased (fig. 2a). The numbers of mast cells in the irradiated group were increased 50 fold in the interstitium and around 10 fold in the peribronchial/perivascular compared to the controls (table 2). Irradiation caused a marked increase of PMNs in BALF, whereas the number of small macrophage-like cells was reduced (table 1).

\section{Effects of IL-2 treatment plus irradiation}

IL-2 together with irradiation caused a greater increase of total cells in the peribronchial and perivascular areas 

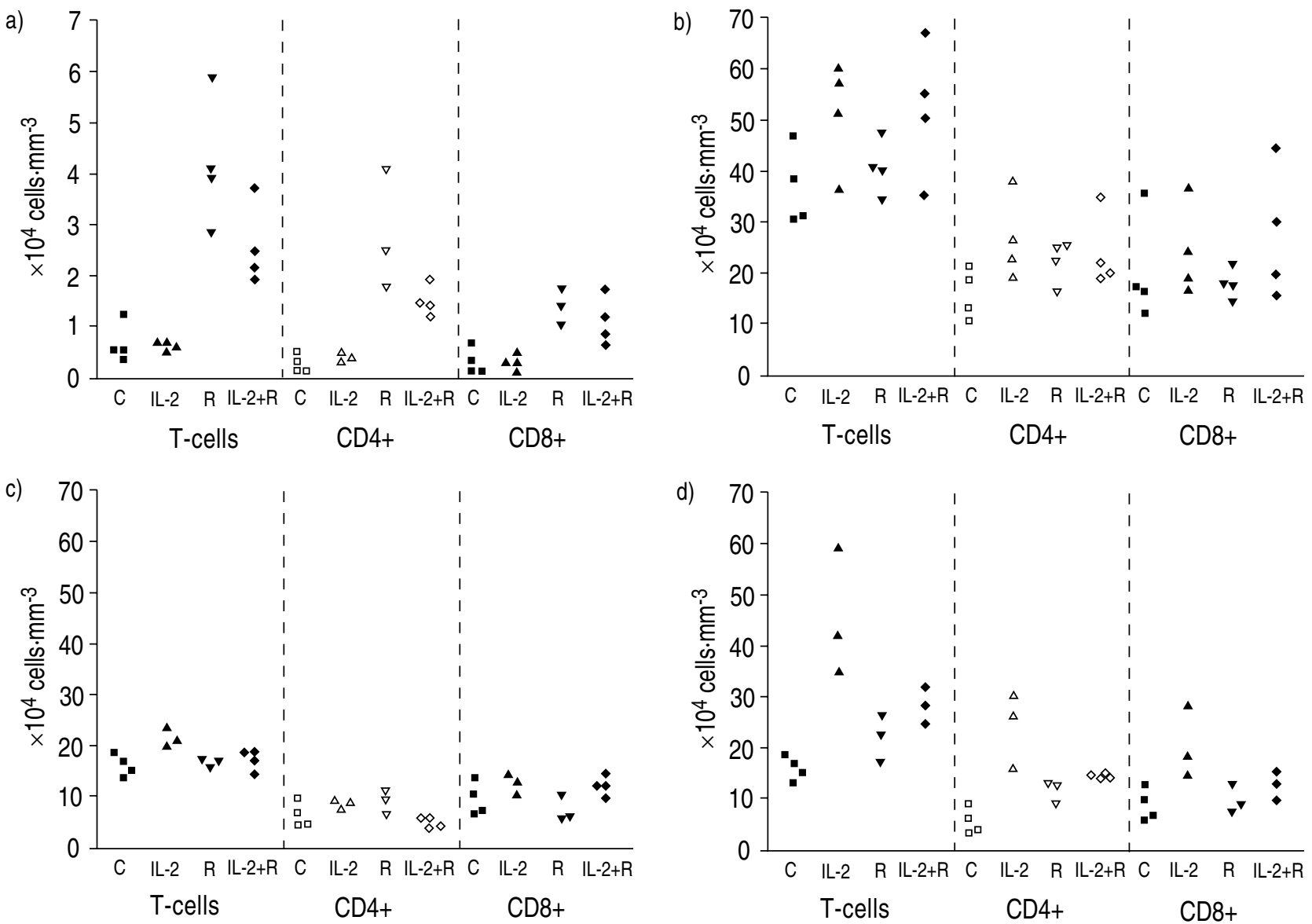

Fig. 2. - Individual data from total numbers of T-cell subsets in lung tissue 6 weeks after treatment. a) alveolar space; b) interstitium; c) peribronchial tissue; d) perivascular tissue. CD4+ and CD8+ T-cells were identified by monoclonal antibodies (MoAbs) recognizing the rat homologue to human CD4 and CD8 antigens, respectively. No statistical analysis was performed due to the low numbers of animals in each group $(n=4)$. To acquire a sufficient evaluation, an area of 10 visual fields with an accumulated area of $0.113 \mathrm{~mm}^{2}$ was required. For abbreviations see legend to figure 1 .

Table 2. - Total numbers of mast cells $\left(\times 10^{4} \cdot \mathrm{mm}^{-3}\right)$ in lung tissue 6 weeks after treatment

\begin{tabular}{lcc}
\hline & Interstitium & $\begin{array}{c}\text { Peribronchial/ } \\
\text { perivascular tissue }\end{array}$ \\
\hline $\mathrm{C}$ & $0.8 \pm 0.1$ & $0.9 \pm 0.1$ \\
$\mathrm{IL}-2$ & $1.0 \pm 0,1$ & $1.7 \pm 0.2^{* *}$ \\
$\mathrm{R}$ & $58.6 \pm 3.7 * * *$ & $14.3 \pm 0.7 * * *$ \\
IL-2+R & $56.3 \pm 6.5^{* * *}$ & $19.7 \pm 1.3^{* * *}$ \\
$\mathrm{R} v s$ IL-2+R & $\mathrm{NS}$ & $* *$ \\
\hline
\end{tabular}

Values are presented as mean \pm sEM. There were six animals in each treatment group and nine controls. **: $\mathrm{p}<0.01 ; * * *$ : $\mathrm{p}<0.001$, compared to control rats. For abbreviations see legend to table 1 .

than did irradiation alone (fig. 1). Because of the limited numbers of animals stained for T-cell typing in each group $(n=4)$, the interpretation of the T-cell data must be performed with care. However, compared to irradiation treatment alone, there was a tendency toward decreased numbers of T-cells, especially CD4+ cells in the alveolar space (fig. 2a). In contrast, the numbers of T-cells, especially CD4+ cells, tended to be elevated in the perivascular area in the group treated with both IL2 and irradiation (fig. 2d). Moreover, addition of IL-2 significantly enhanced the mast cell response caused by irradiation in the peribronchial perivascular area, whilst no significant difference could be seen in the interstitium (table 2). Neither the total cell numbers nor the differential cell counts in BALF were altered when IL2 was given to irradiated rats (fig. 1, and table 1).

\section{Discussion}

The results of this study demonstrate that IL-2 induces an inflammatory response in the lung tissue, as well as in the alveolar space and interstitium. However, we did not find any major additional effects of adjuvant IL-2 treatment on the intense inflammatory reaction caused by irradiation. It was interesting to see that the increased number of inflammatory cells in the alveolar tissue seen histologically after IL-2 treatment was not at all reflected in BALF.

IL-2 is known to activate T-cells, especially CD4+ Thelper cells. Activated T-cells are able to both promote fibrosing inflammation by secreting fibroblast chemotactic and activating factors [20,21], and to influence the activation of mast cells involved in this fibrotic process [22]. These data suggest that lung toxicity in IL-2 
treated patients may be mediated by inflammatory processes induced or enhanced by IL- 2 . The observations in this study show that IL-2, which induces an invasion of inflammatory cells to the lung tissue in nonirradiated rats, is in accordance with such a concept. In this study, however, the absence of additional effects of concomitant administration of IL- 2 on the general inflammatory reaction induced by irradiation was striking, with the exception of the perivascular area. In this particular compartment, the numbers of T-cells show an increase in both groups of irradiated rats, but this effect was even more pronounced in the group where IL-2 only was given. The reason for this is unclear. IL-2 is known to increase systemic vascular permeability as well as pulmonary vascular permeability [23]. Mediators involved in this process may also serve as chemotactic signals attracting inflammatory cells to the vascular compartment [24]. IL-2 was administered subcutaneously and reached the lungs via the systemic vascular route. This may also be an important factor, partly explaining why the inflammatory response after IL-2 administration seems to be higher in the vascular compartment. The effect induced by IL-2 alone in the perivascular tissue was even superior to the inflammatory response caused by irradiation alone. The lack of evident effects in the other compartments suggests that IL-2 and irradiation, respectively, at least as administered in this study, cause inflammatory responses by different mechanisms that do not act synergistically.

BAL is a widely-used tool in studies of inflammatory processes in the peripheral airways. However, it is still unclear to what extent BALF findings reflect the actual inflammatory processes in the peripheral airways [10,25]. The findings in this study show that IL-2 treatment, which reduces the number of inflammatory cells in BALF, is in accordance with a previous clinical observation. We found, in a case report of a single patient that IL-2 treatment decreased the total number of cells in BALF [26]. IL-2 is known to induce an increased production of adhesion molecules from natural killer (NK) cells [26], and possibly also to directly increase the adherence of $\mathrm{T}$ cells [20] as well as monocytes/macrophages [28] in the lung. In the present study, the increased numbers of cells seen in the alveolar space after IL-2 treatment was paralleled by a decrease of cells in BALF. This indicates that IL-2 treatment in vivo also induces an increased adhesiveness of cells situated in the peripheral airways, making BAL analysis in such a situation unreliable or difficult to interpret. Furthermore, IL-2 treatment did not only influence the total cell numbers recovered; the effect also seem to differ between different cell types, with a more pronounced decrease seen in the macrophage fractions.

In summary, even though both irradiation and interleukin-2 treatment separately induce significant inflammatory responses in the lung, no convincing signs of synergistic actions could be seen in the present experimental model. This study clearly supports previous doubts concerning the interpretation of cell recovery in bronchoalveolar lavage fluid, since this could be modified by differences in cell activation and adhesiveness.
Acknowledgements: The skilful technical assistance of J. Pourazar and secretarial assistance of E. Fessé are acknowledged.

\section{References}

1. Glassman AB. Interleukin-2 and lymphokine-activated killer cells: promises and cautions. Ann Clin Lab Sci 1989; 19: 51-55.

2. Eisenthal A, Rosenberg SA. Systemic induction of cells mediating antibody-dependent cellular cytotoxicity following administration of interleukin-2. Cancer Res 1989; 49: 6953-6959.

3. Kradin RL, Kurnick JT, Lazarud DS, et al. Tumourinfiltrating lymphocytes and interleukin-2 in treatment of advanced cancer. Lancet 1989; 1: 577-580.

4. Dunlap NE, Lane VG, Cloud GA, Tilden AB. In vitro natural killer and lymphokine-activated killer activity in patients with bronchogenic carcinoma. Cancer 1990; 66: 1499-1504.

5. Siegel JP, Puri RK. Interleukin-2 toxicity (review). $J$ Clin Oncol 1991; 9: 694-704.

6. Rosenberg SA, Lotze M, Yang JC, Aebersold PM, Linehan, LM, White DE. Experience with the use of high-dose interleukin-2 in the treatment of 652 patients. Ann Surg 1989; 210: 474-484.

7. Bjermer L, Franzén L, Nilsson K, Littbrand B, Ångström T, Henriksson R. Bronchoalveolar lavage of irradiated breast cancer patients; effects of smoking and irradiated volume on inflammatory response. Cancer Res 1990; 50: 2027-2030.

8. Bjermer L, Hällgren R, Nilsson $\mathrm{K}$, et al. Radiationinduced increase in hyaluronan and fibronectin in bronchoalveolar lavage from breast cancer patients is suppressed by smoking. Eur Respir J 1992; 5: 785-790.

9. Nilsson K, Henriksson R, Hellström, S, Tengblad A, Bjermer L. Hyaluronan reflects the prefibrotic inflammation in irradiated rat lung: concomitant analysis of parenchymal tissues and bronchoalveolar lavage. Int $J$ Radiat Biol 1990; 58 (3): 519-530.

10. Klech H, Hutter C. Clinical guidelines and indications for bronchoalveolar lavage (BAL). Report of the European Society of Pneumology Task Group on BAL. Eur Respir Rev 1990; 3: 937-974.

11. Henrikssen R, Widmark A, Bergh A, Damber JE. Interleukin-2 induced regression in the growth of prostatic carcinoma in the rat. Urol Res 1992; 20: 189-91.

12. Lumsden AJ, Codde JP, Gray BN, van der Meide PH. Improved efficacy of doxorubicin by simultaneous treatment with interferon-gamma and interleukin-2. In Vivo 1992; 6: 553-558.

13. Bjermer L, Yi-qing C, Nilsson K, Hellström S, Henriksson R. Tobacco smoke exposure suppresses the radiationinduced inflammation in the lung: a study of bronchoalveolar lavage and ultrastructural morphology in rat. Eur Respir J 1993; 6: 1173-1180.

14. Strobel S, Miller HRP, Ferguson A. Human intestinal mucosal mast cells: evaluation of fixation and staining techniques. J Clin Pathol 1981; 34: 851-858.

15. Sternberger LA. Immunohistochemistry. New York, Viley Medical Publications, John Wiley \& Sons, 1979.

16. Brown WRA, Barclay AN, Sunderland CA, Williams AF. Identification of a glycophorine-like molecule at the cell surface of rat thymocytes. Nature 1981; 289: 456460.

17. Brideau RJ, Carter PB, McMaster WR, Mason DW, Williams AF. Two subsets of rat T-lymphocytes defined 
with monoclonal antibodies. Eur J Immunol 1980; 10: 609-615.

18. Barclay AN. The localization of populations of lymphocytes defined by monoclonal antibodies in rat lymphoid tissues. Immunology 1981; 42: 593-600.

19. Kaplow LS. Substitute for benzidine in myeloperoxidase stains. Am J Clin Pathol 1975; 63: 451.

20. Hampson F, Monick M, Peterson MW, Hunninghake GW. Immune mediators increase adherence of T-lymphocytes to human lung fibroblasts. Am J Physiol 1989; 256: C336-C340.

21. Spits H, de Waal Malefyt R. Functional characterization of human IL-10. Int Arch Allergy Appl Immunol 1992; 99: 8-15.

22. Levi-Schaffer F, Segal V, Shalit M. Effects of interleukins on connective tissue type mast cells co-cultured with fibroblasts. Immunology 1991; 72: 174-180.

23. Harms BA, Pahl AC, Pohlman TH, Conhaim RL, Starling JR, Storm FK. Effects of interleukin-2 on pulmonary and systemic transvascular fluid filtration. Surgery 1989; 106: 339-345.

24. Klausner JM, Goldman G, Skornick Y, et al. Interleukin2-induced lung permeability is mediated by leukotriene B4. Cancer 990; 66: 2357-2364.

25. Haslam PL. Evaluation of alveolitis by studies of lung biopsy. Lung 1990; 168: 984-992.

26. Bjermer L, Grönberg H, Roos G, Henriksson R. Interleukin2 administration intravenously and intrapleurally in a patient with primary pulmonary adenocarcinoma: cellular responses in peripheral blood, intrapleural fluid and bronchoalveolar lavage. Biotherapy 1993; 6: 1-7.

27. Rabinowich H, Herberman RB, Whiteside TL. Differential effects of IL-12 and IL-2 on expression and function of cellular adhesion molecules on purified human natural killer cells. Cell lmmunol 1993; 152: 481-498.

28. Melder RJ, Walker E, Herberman RB, Whiteside TL. Adhesion characteristics of human interleukin-2-activated natural killer cells. Cell Immunol 1991; 132: 177-192. 